\title{
Synergy Between the Credibility Revolution and Human Development in Africa
}

\author{
Adeyemi Adetula ${ }^{1 *}$, Patrick S. Forscher ${ }^{1}$, Dana Basnight-Brown ${ }^{3}$, Soufian Azouaghe ${ }^{1,2}$, \\ Nihal Ouherrou ${ }^{4}$, Abdelilah Charyate ${ }^{5}$, Nina Hansen ${ }^{6}$, Gabriel Agboola Adetula ${ }^{7}$, \\ Hans IJzerman 1,8 \\ *adeyemi.adetula@univ-grenoble-alpes.fr
}

Author Note: AA wrote the first draft; PSF \& HIJ provided substantial revisions; all other authors provided critical comments and revisions.

\author{
Affiliations: \\ ${ }^{1}$ LIP/PC2S, Université Grenoble Alpes \\ ${ }^{2}$ Université Mohammed V de Rabat \\ ${ }^{3}$ United States International University-Africa \\ ${ }^{4}$ Université Chouaib Doukkali, Université Paul Valéry Montpellier 3 \\ ${ }^{5}$ Université Ibn Tofail \\ ${ }^{6}$ University of Groningen, The Netherlands \\ ${ }^{7}$ Adekunle Ajasin University \\ ${ }^{8}$ Institut Universitaire de France (IUF)
}

\begin{abstract}
Spurred by a crisis in their confidence in past findings, psychology in North America, Europe, and Australia has been undergoing a credibility revolution, which has spurred the development and popularization of open science practices to improve the research process. Alongside this development, a broad array of stakeholders have noted that African science is at its own crossroads, as investments in this sector can facilitate human development on the continent. Here we argue that these two movements can facilitate each other: psychology in North America and Europe can benefit from stronger psychology research communities on the African continent, while African scientists can benefit from credible evidence generated through open, freely-available open science practices and tools. However, this synergy will only materialize if a wide array of stakeholders invest in African science through providing resources, training, and specially adapted research tools while simultaneously avoiding ethical pitfalls such as corruption and research colonialism.
\end{abstract}




\section{Synergy Between the Credibility Revolution and Human Development in Africa}

In North America, Europe, and Australia, psychological science is at a crossroads. Practices that were once deemed rigorous now appear to lead to non-replicable findings. The ensuing "credibility crisis" led to a period of intense scrutiny of problems in science, which itself has led to a "credibility revolution" to develop initiatives to fix those problems (Vazire, 2018). These initiatives borrow liberally from other openness movements, such as the free software movement, and aim to increase the accessibility of science, provide free infrastructure to support rigorous science, develop practices that lead to credible evidence, and make science more collaborative. Despite the ferment inspired by the credibility crisis, the innovations inspired by this crisis have been slow to spread outside the confines of North America, Europe, and Australia. Nor have the innovators grappled substantially with problems that affect the credibility of psychological research, but not via poor replicability, such as the overreliance on narrow convenience samples (Arnett, 2009; Henrich et al., 2010; Tiokhin et al., 2019) and the limited applicability of psychology to applied problems (Premachandra \& Lewis, 2020).

Alongside this transition in psychology, African science is at a crossroads of its own. In the wake of the devastation wrought by colonialism, African nations have struggled to build the infrastructure and institutions necessary to support a happier, healthier, and more educated population. Intergovernmental organizations such as the UN also increasingly recognize African development as a broadly important goal; with 17\% of the world's population that should increase to $42 \%$ by century's end (Roser et al., 2013), the world cannot realize goals important trans-national goals, such as the UN's Sustainable Development Goals (https://sdgs.un.org/goals), without engaging Africa. Research and postsecondary education can assist with this development through conducting robust research to help with evidence-based policy, building human capital, and assisting with technological 
catch-up (Atickem et al., 2019; Bloom et al., 2014). Yet enrolment in higher education in Africa has lagged due to problems that include low funding, inadequate infrastructure, and political instability (Nsamenang, 2007; Ojiji, 2015). This low enrolment is reflected in psychology, a research field that Cameroonian psychologist A. Bame Nsamenang (2007) described as "nascent" in most parts of sub-Saharan Africa.

We believe that there is synergy between the credibility revolution in psychology and efforts to use research and education to meet human development goals in Africa. This synergy occurs because of the credibility revolution's emphasis on building freely accessible processes and tools. These processes and tools have the potential to accelerate the development of the human capital and infrastructure necessary to build stronger, more vibrant research communities throughout the continent (Draft Text of the UNESCO Recommendation on Open Science, 2021; Mwangi et al., 2021; Onie, 2020). If the credibility revolution's newly-developed processes and tools are applied to concrete problems that accelerate human development, psychology could even reach a goal it has long aspired to, namely using its research to directly assist in solving big social problems. Psychology also stands to benefit from stronger psychology research communities in Africa; not only because these stronger communities could lead the research initiatives that help make psychological findings more generalizable to Africans, but also because such communities could push psychology to study issues currently outside its mainstream.

This article attempts to bridge the gap between the credibility revolution in North America, Europe, and Australia and the movement to increase human development in Africa. The article thus serves dual audiences. For readers in North America, Europe, and Australia, it describes the current state of African psychology research and how decision-makers can facilitate the spread of open science practices in Africa, thereby facilitating the development of global research community that studies problems relevant to humanity writ large. For 
readers from Africa, it provides an overview of the credibility revolution and how the open science practices emerging from this revolution can facilitate stronger research communities in Africa. Our hope is that this article can benefit both of these audiences.

\section{The credibility revolution in North America, Europe, and Australia}

The credibility crisis traces its roots to 2011 , when the well-regarded social psychologist, Daryl Bem, published an unusual article in the world's top social psychology journal, the Journal of Personality and Social Psychology. This article was unusual because of its central claim: that undergraduate students who he had recruited from Cornell University in Ithaca, New York, USA could be affected by events that hadn't yet occurred (Bem, 2011). In other words, these undergraduates could sense the future. What's more, Bem used methods that met or exceeded social psychology's standards of rigor at that time. This left one of two possible explanations: either everything we knew about physics was wrong, or those methods were not as rigorous as the research community once believed (see Francis, 2012; Schimmack, 2012; Shrout \& Rodgers, 2018).

This realization spurred a trend of large replication studies designed to examine the credibility of past findings. These replication studies took a protocol that had been previously used to claim a particular discovery, then recruited new participants with that protocol - often a much greater number than the original paper achieved. The replicators were able to achieve these large sample sizes by forming very large collaborations across many labs, thereby allowing them to investigate a past finding with much greater precision than was feasible for any lab on its own (Forscher, Wagenmakers, et al., 2020). The findings of these collaborative replication studies were worrying; across 77 large replication studies, 43 (56\%) reported statistically significant results in the same direction as the original, with effect sizes that were only $53 \%$ as large as the original (Nosek et al., 2021). Although these studies are not representative of psychology as a whole, and although there is no consensus about what the 
replication rate of psychological research ought to be, it is at least clear that current methods and practices led to a literature that substantially overstated the evidence behind many findings (Spellman, 2015; Vazire, 2017). The task, then, was to identify problems that undermine research credibility and identify practices to fix those problems.

The result was an explosion of research on practices to improve the credibility of psychology research. Most of these practices focus on bringing something into the open that was previously hard to access. For this reason, we call them "open science practices", though this broad label obscures major differences in goals and motivations (Fecher \& Friesike, 2014). We believe these practices have the potential to improve many aspects of psychological research. However, much of the focus of the credibility revolution has been on addressing the problem that kicked off the revolution, namely poor replicability of findings. For this reason, the innovations of the credibility revolution have yet to be fully applied to problems outside replicability. Most replications, for example, focus on the replication of low-cost studies that can be completed online with convenience samples drawn from college classrooms or platforms like mTurk (Gervais, 2020). This feature means that, even if the credibility of the evidence improves as a result of the new replication studies, the findings still have limited applicability to large swathes of humanity and their problems.

\section{The research landscape in Africa}

Africa is an enormously diverse continent, home to 1.3 billion people from speaking over 1000 languages across more than 50 countries. The amount of ethnic diversity in Africa is also high: in sub-Saharan Africa (the region that excludes Africa's North coast), there are about 35\% more ethnic groups per country than any other world region (Fearon, 2003, Table 1). Finally, African nations are each subject to their own unique political circumstances, which deeply impact government support for research and higher education. These factors complicate any attempt to clearly summarize Africa's research landscape. 
What does unite the African continent is a shared history of subjugation to colonizing powers. Following the Scramble for Africa, a period formalized by the Berlin Conference in 1884 and capped by World War I in 1914, only Liberia and Ethiopia remained free of colonial rule. The colonizers imposed administrative regimes with arbitrary demarcation points that often had little to no relationship with existing ethnic, linguistic, cultural, and religious boundaries. These regimes prioritized the extraction of local resources, which were then exploited for the economic benefit of the colonizing power (Michalopoulos \& Papaioannou, 2020). Decolonization only started after World War II and continued until 1975, yet the nation-states formed in the wake of decolonization were moulded after colonial administrations and thus grouped together people whose main reason for unification was a shared history of exploitation by the same colonial regime. These features left a legacy of political instability that has obstructed the development of strong academic research institutions (Nsamenang, 2007).

As a result, university-housed research communities in most regions of Africa, and particularly those in psychology, are quite new. In the post-colonial period of the 1960 s, the United Nations made a concerted push for the newly-independent African nations to establish systems of secondary and tertiary education. In the 1970s, these priorities shifted to universal primary education, with tertiary education being largely neglected (Bloom et al., 2014). University-housed research suffered (Bloom et al., 2014), stymied by high workloads, poor IT infrastructure and an unstable power supply, burdensome administrative requirements, inadequate funding, and corruption (Atickem et al., 2019; Nsamenang, 2007; Ojiji, 2015).

Today, the political situations in most African countries have stabilized and most economies are growing, sometimes quite rapidly (Young, 2012). Higher education is following suit: enrolment in tertiary education in Africa grew by 170\% between 1999 and 2002 (ICEF Monitor, 2015). Despite this impressive growth, an enormous gap in research 
capacity persists (Atickem et al., 2019). To understand the scale of this gap, consider that higher economic output reflects, in part, an expansion in the available goods and services available to the average person. The average GDP per capita in the United States was $\$ 54,225$, about 15 times the value of $\$ 3,467$ for sub-Saharan Africa (Roser, 2013). To make this difference concrete, our US-based readers might imagine that you have a pool of $\$ 2,000$ for a particular research project but everything about that research - from participant recruitment costs, to data analysis software, to publishing charges, to fees for review by Institutional Review Boards - costs 15 times what you currently pay for it. Moreover, due to poor institutional resources, the $\$ 2,000$ might need to come out of your own personal funds, where it must compete with the money needed to cover your basic living expenses (Atickem et al., 2019).

In this context, it is no wonder that discussions of "building research capacity" in Africa often prioritize research areas that can directly resolve concrete problems for Africans, such as maternal health, plant breeding, sanitation and infectious diseases (Nordling, 2018; The World Bank Group \& Elsevier, 2014). African researchers themselves tend to focus on applied research (Hountondji, 1990). Psychology may need to demonstrate its direct applicability to African problems if it wishes to attract the attention of talented prospective African researchers.

\section{How open science practices can contribute to human development}

Herein lies the potential for cross-fertilization between the "credibility revolution" and efforts to expand human development in Africa. Although the "open science practices" used in psychology's credibility revolution have largely been applied to improve research credibility via better replicability, they can in principle be applied to address a broad range of problems. For the purposes of this article, we separate the practices into four groups according to their primary aim. Initiatives to increase research accessibility allow researchers 


\begin{tabular}{|c|c|c|c|}
\hline Category & Name & Link & Purpose \\
\hline \multirow{4}{*}{ Accessibility } & PsyArXiv & https://psyarxiv.com/ & $\begin{array}{l}\text { Freely share and access preprints related } \\
\text { to psychology }\end{array}$ \\
\hline & AfricArXiv & https://info.africarxiv.org/ & $\begin{array}{l}\text { Freely share and access preprints related } \\
\text { to Africa }\end{array}$ \\
\hline & MERLOT & $\underline{\text { https://info.merlot.org/ }}$ & Freely share and access teaching materials \\
\hline & Sci-Hub & https://en.wikipedia.org/wiki/Sci-Hub & $\begin{array}{l}\text { Freely and illegally access journal } \\
\text { research articles }\end{array}$ \\
\hline \multirow{7}{*}{ Infrastructure } & Open Science Framework & https://osf.io/ & $\begin{array}{l}\text { Freely share and access research products, } \\
\text { including study materials, research code, } \\
\text { datasets, and protocols }\end{array}$ \\
\hline & Github & $\underline{\text { https://github.com/ }}$ & Freely share and access research code \\
\hline & Dataverse & $\underline{\text { https://dataverse.org/ }}$ & Freely share and access research data \\
\hline & FigShare & $\underline{\text { https://figshare.com/ }}$ & $\begin{array}{l}\text { Freely share and access up to } 5 \mathrm{~GB} \text { of } \\
\text { space }\end{array}$ \\
\hline & PsychoPy & https://www.psychopy.org/ & Freely program research experiments \\
\hline & $\mathrm{R}$ & https://www.r-project.org/ & Freely program analysis code \\
\hline & RStudio & https://www.rstudio.com/ & Free, user-friendly interface for $\mathrm{R}$ \\
\hline \multirow{3}{*}{ Credibility } & Registered Reports & $\underline{\text { https://osf.io/rr/ }}$ & $\begin{array}{l}\text { Get journal peer review and approval } \\
\text { before you collect research data }\end{array}$ \\
\hline & OSF Preregistrations & $\underline{\text { https://osf.io/prereg/ }}$ & $\begin{array}{l}\text { Store a detailed study protocol before you } \\
\text { collect research data }\end{array}$ \\
\hline & AsPredicted & $\underline{\text { https://aspredicted.org/ }}$ & $\begin{array}{l}\text { Store a detailed study protocol before you } \\
\text { collect research data }\end{array}$ \\
\hline \multirow{6}{*}{ Networking } & ManyLabs: Africa & $\underline{\text { https://osf.io/dvwzc/ }}$ & $\begin{array}{l}\text { A new collaborative project to provide } \\
\text { training to African researchers on open } \\
\text { science practices and explore the } \\
\text { generalizability of research findings in } \\
\text { Africa and the West }\end{array}$ \\
\hline & $\begin{array}{l}\text { The Psychological } \\
\text { Science Accelerator }\end{array}$ & $\underline{\text { http://psysciacc.org }}$ & $\begin{array}{l}\text { A large, standing network that conducts } \\
\text { big team science psychology projects on } \\
\text { all five populated continents }\end{array}$ \\
\hline & $\begin{array}{l}\text { Collaborative Replications } \\
\text { and Education Project }\end{array}$ & https://osf.io/wfc6u/ & $\begin{array}{l}\text { A large, standing network that uses big } \\
\text { team science to train bachelor- and } \\
\text { master-level students }\end{array}$ \\
\hline & ManyBabies & https://manybabies.github.io/ & $\begin{array}{l}\text { A large, standing network that conducts } \\
\text { big team science projects focused on } \\
\text { infancy research }\end{array}$ \\
\hline & StudySwap & https://osf.io/meetings/studyswap/ & $\begin{array}{l}\text { A platform to develop collaborations and } \\
\text { exchange resources across labs }\end{array}$ \\
\hline & ReproducibiliTea & https://reproducibilitea.org/ & $\begin{array}{l}\text { A platform to set up and conduct journal } \\
\text { clubs at local institutions }\end{array}$ \\
\hline
\end{tabular}

Table 1. Five categories of open science practice and initiatives that fit each category. 
to freely share and access written research articles. Initiatives to provide infrastructure aim to provide free resources to make the research process easier. Initiatives to improve credibility aim to improve the quality of research evidence. Finally, networking initiatives aim to increase ties between researchers, often via large collaborative research projects. Here we describe several practices in each category and provide resources to learn more.

The accessibility initiatives will perhaps be most familiar to an African audience. These initiatives note that, after research is published as an article in a scientific journal, the publisher takes the article copyright and locks the article behind a paywall. From the perspective of promoting research credibility, these paywalls are a problem because they restrict access to information that is needed to inspect evidence credibility. However, paywalls are also a problem from an equity perspective because they restrict the access of the very people who might most benefit from scientific knowledge and innovation.

Most Africans will be familiar with one solution to this problem (Huang et al., 2020): a journal business model that allows the article to be accessed for free, as long as the submitting author pays an "article processing fee" to the journal. Under these open access business models, the journal keeps the article copyright but the journal imposes an additional fee on article submitters. Unfortunately, open access business models are not ideal for article authors at low-resource institutions. This is because the business model shifts the costs of maintaining digital versions of an article onto authors, who may not be able to pay this fee if they are at an institution with low financial resources. Some open access journals can even be "predatory" in the sense that they provide publications to researchers in exchange for a fee while doing little to ensure that their published papers have scientific merit (Mouton \& Valentine, 2017; Xia et al., 2015). Not all open access journals are predatory in this sense; journals are "predatory" only if they are strictly money-making enterprises that provide little 
to no quality control, with the result that they allow the publication of pseudo-scientific or nonsense articles because the authors of these articles nevertheless paid a publication fee.

Beyond open access journals, the credibility revolution has popularized some additional initiatives that are not journal-focused. Many of these initiatives focus on increasing the accessibility of a version of the article where authors keep the copyright: the version just after article acceptance, but before the journal does any formatting or copyediting of the accepted article, often called the preprint (for a comprehensive guide, see Moshontz et al., 2020). Authors have the right to share this version of the article. Thus, a variety of websites have sprung up to freely host this version of the article, such as PsyArXiv and AfricArXiv. These websites also assign Digital Object Identifiers (DOIs) to the articles they host, which allow the preprints to be indexed by databases, such as the database maintained by Google Scholar. Preprint websites differ from journals in that they do not charge anyone a fee, but also do not provide peer review or copy-editing. Journals often have special policies that govern how they handle preprints; authors should consult those policies before they post preprints to these servers. The Sherpa database provides a searchable database of those policies (https://v2.sherpa.ac.uk/romeo/).

One final accessibility initiative deserves mention. The article database Sci-Hub provides access to the published versions of articles (post copy-editing and journal formatting) entirely for free. However, the use of Sci-Hub is illegal in most countries. Thus, we cannot recommend the use of this service - particularly for African researchers, whose libraries may not be able to afford the expensive fees that most journals charge.

The infrastructure initiatives aim to make a certain aspect of the research process easier by providing free infrastructure for that research process. These initiatives are useful for African researchers because they can substantially lower the costs of creating a vibrant digital infrastructure that supports scientific activity. For example, the Open Science 
Framework (https://osf.io) is a general-purpose website created and maintained by the Center for Open Science that allows researchers to store their research materials, data, analysis scripts, and other research artefacts. At any time, a researcher may choose to make these materials public, in which case they may be accessed by others for free. This can benefit both researchers who access the open materials, because they can re-use the materials for their own research, and the researcher who shares their materials, because their reputation and credibility are enhanced (Ebersole et al., 2016). The general research ecosystem also benefits because free access to research materials minimizes duplication of effort. In addition to the general-purpose Open Science Framework, there are many specialty initiatives that focus on allowing the free sharing of one type of research product, such as research code (Github; https://github.com/) or research data (Dataverse; https://dataverse.org/).

This category also includes many free and open source computing languages designed to facilitate research computing. These free tools thus minimize the financial barriers to writing digital scientific tools. These languages include PsychoPy, which facilitates the programming of psychology experiments, and $\mathrm{R}$, which facilitates the analysis of research data. These languages often take time to learn, but there is no financial cost to using them. In addition, a great deal of tutorial materials exist for learning these languages. For a tutorial for PsychoPy, see https://www.psychopy.org/coder/tutorial1.html; for a tutorial for R, download the free R-based programming environment, RStudio, and see https://r4ds.had.co.nz/.

The credibility initiatives consist of workflows and policy frameworks that help ensure research findings are credible. These tools arose to ensure that research findings can be relied upon and are especially important for research that has applied or policy implications, a type of research that is often of interest to African researchers. The most prominent of these initiatives are Registered Reports, a framework for a research article format in which authors submit research protocols that are peer reviewed before any data 
collection occurs. If the protocol is deemed sufficiently rigorous during the peer review process, it gains "in principle acceptance": as long as the researchers follow the protocol during the collection and analysis of data, the paper is accepted, regardless of how the data turn out. This policy framework helps protect against the selective publication of positive results, a practice that is prevalent in the social sciences and that undermines the credibility of entire research fields (Scheel et al., 2020). Many journals already support the Registered Report format, and their number continues to grow; for a list, see https://cos.io/rr.

A second type of credibility initiative is websites for pre-registering a study protocol. Essentially, a researcher prepares the first part of a Registered Report and archives the protocol on one of these websites prior to running the study. This pre-written protocol allows outside researchers to evaluate the match between the protocol and the final article and check whether deviations from protocol are justified. Under a mode of science that prioritizes falsifying pre-specified predictions, preregistration increases the credibility of the final evidence (Kaplan \& Irvin, 2015; Lakens, 2019). Preregistration does not necessarily involve any formal peer review of the written protocols and is not tied to any specific journal. Thus, unlike a Registered Report, a researcher who preregisters one of their studies is not limited in their choice of journals.

Finally, the networking initiatives aim to increase the connections between researchers, often via large research collaborations. These initiatives can thus facilitate collaborations both among Africans and between Africans and non-Africans. A few of these initiatives are aimed at increasing social connections between members. One of these is ReproducibiliTea, a platform for setting up journal clubs at your own institution. However, some of these networks are more focused on completing very large, often international, collaborative projects. These "big team science" initiatives (Forscher, Wagenmakers, et al., 2020) play a central role in "scaling up" the amount of resources that are invested into 
replication studies so that claims can be carefully examined. However, big team science can also deploy large numbers of people on a new study of central importance. For example, one prominent big team science organization, the Psychological Science Accelerator, initiated a project to investigate the psychological aspects of COVID-19 (Forscher, Paris, et al., 2020). By pooling resources across the large collective, this project was able to recruit over 47,000 participants from 110 countries, using materials in 44 languages for three primary research studies. Big team science organizations also exist for infancy research (the ManyBabies initiative; Byers-Heinlein et al., 2020) and for teaching undergraduates the research process via replication studies (the Collaborative Replication and Education Project or CREP; Wagge, Baciu, et al., 2019; Wagge, Brandt, et al., 2019). Readers will find a variety of materials useful for integrating the CREP model of replication research into undergraduate classes, including links to tutorial videos subtitled in a variety of African languages, at https://corelab.blog/crep-africa/.

As of yet, big team science organizations do not have a strong presence of African researchers. For example, as of 2020 , only about $2 \%$ of the membership of the Psychological Science Accelerator was from Africa (Paris et al., 2020). We believe this lack of African members represents both a gap and an opportunity: a gap because these organizations need a stronger African presence if they are to be truly international, and an opportunity because African researchers who join these organizations can become integrated into broad networks dedicated to impactful research. 


\begin{tabular}{|c|c|c|c|c|c|c|c|}
\hline \multirow[b]{2}{*}{ Category } & \multirow[b]{2}{*}{ Barrier } & \multirow[b]{2}{*}{ Interventions } & \multicolumn{5}{|c|}{ Stakeholders } \\
\hline & & & $\mathbf{U}$ & $\mathbf{S}$ & $\mathbf{F}$ & $\mathbf{J}$ & $\mathbf{R}$ \\
\hline \multirow{3}{*}{ Resources } & \multirow{2}{*}{$\begin{array}{l}\text { Financial resources in } \\
\text { Africa are limited }\end{array}$} & $\begin{array}{l}\text { Provide small, unrestricted grants with few } \\
\text { accounting requirements to African researchers }\end{array}$ & $\mathbf{X}$ & $\mathbf{X}$ & $\mathbf{X}$ & & \\
\hline & & $\begin{array}{l}\text { Provide automatic waivers for Article Processing } \\
\text { Charges that overstretch limited financial resources for } \\
\text { African researchers }\end{array}$ & & & & $\mathbf{X}$ & \\
\hline & $\begin{array}{l}\text { Infrastructure and facilities } \\
\text { are limited and unreliable }\end{array}$ & $\begin{array}{l}\text { Provide internet grants to allow African researchers to } \\
\text { purchase better internet-based resources }\end{array}$ & $\mathbf{X}$ & $\mathbf{X}$ & $\mathbf{X}$ & & \\
\hline \multirow{3}{*}{ Training } & \multirow{3}{*}{$\begin{array}{l}\text { Training is needed to use } \\
\text { open science practices }\end{array}$} & $\begin{array}{l}\text { Create a train-the-trainer program for African } \\
\text { researchers, which can focus on encouraging } \\
\text { interactive online tutorials, lectures, workshops and } \\
\text { provide certificates of participation }\end{array}$ & $\mathbf{X}$ & $\mathbf{X}$ & & & $\mathbf{X}$ \\
\hline & & $\begin{array}{l}\text { Organize African research-focused training events } \\
\text { such as workshops, seminars, and talks on how to } \\
\text { access and adopt cutting-edge research resources and } \\
\text { practices }\end{array}$ & $\mathbf{X}$ & $\mathbf{X}$ & $\mathbf{X}$ & & $\mathbf{X}$ \\
\hline & & $\begin{array}{l}\text { Establish, support, and fund open science labs in } \\
\text { Africa, which can serve as designated research centers } \\
\text { to advance open science practices }\end{array}$ & $\mathbf{X}$ & $\mathbf{X}$ & $\mathbf{X}$ & & $\mathbf{X}$ \\
\hline \multirow{5}{*}{$\begin{array}{l}\text { Research } \\
\text { tools }\end{array}$} & \multirow{2}{*}{$\begin{array}{l}\text { Measures of psychological } \\
\text { processes developed in the } \\
\text { US and EU may not } \\
\text { generalize to Africa }\end{array}$} & $\begin{array}{l}\text { Conduct exploratory research to adapt existing } \\
\text { measures and develop new ones }\end{array}$ & & & $\mathbf{X}$ & & $\mathbf{X}$ \\
\hline & & $\begin{array}{l}\text { Create easily-accessible databases of measures and } \\
\text { their translations or adaptations, along with evidence } \\
\text { about their validity in different populations }\end{array}$ & & & $\mathbf{X}$ & & $\mathbf{X}$ \\
\hline & $\begin{array}{l}\text { Many existing tools are } \\
\text { exclusively in English }\end{array}$ & $\begin{array}{l}\text { Create and fund translations of existing tools into } \\
\text { different languages, including the indigenous languages } \\
\text { of Africa }\end{array}$ & & & $\mathbf{X}$ & & $\mathbf{X}$ \\
\hline & \multirow{2}{*}{$\begin{array}{l}\text { Mainstream research } \\
\text { questions may not be } \\
\text { relevant to Africans }\end{array}$} & Conduct research on practical problems in Africa & & & & & $\mathbf{X}$ \\
\hline & & $\begin{array}{l}\text { Actively engage African researchers in the early } \\
\text { stages of the research porcess }\end{array}$ & & & & & $\mathbf{X}$ \\
\hline \multirow{4}{*}{ Ethics } & $\begin{array}{l}\text { Predatory journals let } \\
\text { African researchers engage } \\
\text { in a pay-to-play publishing } \\
\text { schemes }\end{array}$ & $\begin{array}{l}\text { Create African open access overlay journals on } \\
\text { preprint servers that will lower the incentive to publish } \\
\text { in predatory journals }\end{array}$ & $\mathbf{X}$ & $\mathbf{X}$ & $\mathbf{X}$ & $\mathbf{X}$ & \\
\hline & $\begin{array}{l}\text { Institutionalised exploitative } \\
\text { practices rob African } \\
\text { researchers of funds and } \\
\text { exacerbate working } \\
\text { conditions }\end{array}$ & $\begin{array}{l}\text { Establish research integrity offices led by African } \\
\text { researchers and morally and financially supported by } \\
\text { North American and European researchers }\end{array}$ & $\mathbf{X}$ & & & & $\mathbf{X}$ \\
\hline & \multirow{2}{*}{$\begin{array}{l}\text { Non-African researchers } \\
\text { practice research } \\
\text { colonization by using } \\
\text { African researchers as data } \\
\text { collectors without giving } \\
\text { adequate credit or } \\
\text { compensation }\end{array}$} & $\begin{array}{l}\text { Adopt contributorship systems to document fine- } \\
\text { grained contributions to research }\end{array}$ & & & & $\mathbf{X}$ & $\mathbf{X}$ \\
\hline & & $\begin{array}{l}\text { Use collaboration agreements at the start of projects } \\
\text { to set explicit expectations about expected } \\
\text { contributions and systems of credit and compensation }\end{array}$ & & & & & $\mathbf{X}$ \\
\hline
\end{tabular}

Table 2. Barriers to expanded research capacity and interventions to address those barriers. $U$ $=$ Universities; $\mathrm{S}=$ Scientific Societies; $\mathrm{F}=$ Funders; $\mathrm{J}=$ Journals; $\mathrm{R}=$ Researchers. 


\section{Broadening the open science tent in Africa}

Even though we believe open science practices can facilitate the development of the capacity to conduct psychology research in Africa, they are not themselves sufficient due to lingering barriers to African research capacity. Fully addressing these barriers will require concerted effort on multiple fronts from the many stakeholders, African and non-African, that comprise the scientific ecosystem. Here we describe some of the steps these stakeholders can take to facilitate and enhance the impact of the open science practices from the previous section. Our suggested steps fall into four categories: resources, training, research tools, and ethics (see Table 2).

The first category of barriers, a lack of financial and non-financial resources, is the primary barrier to additional research infrastructure that is mitigated by the use of open science practices. This is because open science practices tend to emphasize the use of free or open-source tools to make up for the lack of pre-existing infrastructure. Yet these open science practices cannot by themselves compensate for the resource restrictions that many African scientists face. For example, many African scientists lack reliable internet, which is a prerequisite for using most of the open science resources we previously described; thus, internet grants can make the use of free open science tools more feasible. In the era of online conferences, these grants can also greatly facilitate the participation of African scientists in the global academic commons. Restricted research funding means that, for many African scientists, even small grants can be instrumental for completing research projects - as long as these grants are not saddled with burdensome accounting restrictions that make the money too much of a hassle to be worth using. Finally, although we have emphasized the use of preprint servers rather than open access journals, those journals that do use an open access model can address resource-related barriers by providing waivers of article processing 
charges with few bureaucratic requirements to researchers from low-income countries (Nabyonga-Orem et al., 2020).

Barriers related to training refer to the fact that, even though open science practices often rely on freely-accessible infrastructure, using this infrastructure requires specialist training. At first, some of this training may need to come from North American and European sources due to the better-developed research cultures and infrastructures in these world regions. However, we believe training activities should emphasize establishing grassroots reservoirs of knowledge and skills in Africa so that, eventually, most training comes from local rather than foreign sources. Thus, in addition to activities such as African-focused workshops, training activities should emphasize train-the-trainer programs and Africa-based "open science labs" that serve as training centers for open science practices. Ideally, training initiatives are also integrated into existing university curricula so that they do not have to compete with the resources for general scientific training.

A third category of barriers are those related to research tools that may not be adapted for African realities. For example, most research tools are designed and implemented in English. Although many people in African countries speak English, Africa is highly multilingual. Translating these research tools to other languages using, at a minimum, automatic translation software such as that provided by DeepL or Google Translate is therefore one way to ensure that more Africans are able to use these research tools. These automated tools should only be a last resort; tools that are comprehensible in local languages will be highly re-usable and have a greater chance for lasting impact.

However, the research tool barriers are not merely linguistic. Existing measures of psychological processes may not even be applicable in a specific African culture. Such measures may need extensive cultural adaptation, and the target psychological process may not even exist at all. Facilitating such time-consuming measurement work will also require a 
comprehensive database of psychological measures, their adaptations, and evidence about their validity in different cultures. In addition, some psychological processes may exist Africa that have no clear equivalents in North America or Europe. Descriptive, qualitative, and exploratory approaches that are co-designed with African researchers and involve these researchers at later stages at all stages are necessary to identify and understand these processes in their original context. This descriptive work contrasts with approaches that take North American and European as a baseline against which African psychology is compared (Hansen \& Heu, 2020).

Even more radically, psychology as it is currently constituted may simply study topics that are uninteresting or irrelevant to stakeholders in Africa. To make the case that psychology research is worth the investment of Africa's limited education funds, psychology may need to put a more central focus on studying problems directly relevant to Africa's ongoing concerns, such as general human development. This may mean focusing on solving practical problems, such as those related to maternal health and the transmission of infectious disease (for similar arguments about the Arab region, see Saab et al., 2020). Trans-national benchmarks such as the UN's Sustainable Development Goals (https://sdgs.un.org/goals) may provide a useful guide for the sorts of topics that can directly assist with African development; psychology could be especially useful for attaining SDG2 (zero hunger) and SDG3 (good health and well-being).

The final category of barrier, ethics, refers to ethical pitfalls that can short-circuit the development of robust psychology research communities in Africa. One of these pitfalls relates to an issue we mentioned previously, the existence of predatory journals that take advantage of pressures to hit publication metrics by offering publications in exchange for a fee, with little regard for the quality of the finished research. We believe these pressures to publish can be redirected into more productive avenues by leveraging the preprint servers that 
have developed as part of the credibility revolution's accessibility initiatives. The preprint servers provide a place to deposit papers; one can turn these preprints into publications by developing so-called "overlay journals" that peer review and curate, at no charge, highquality papers that fit a particular theme on a preprint server (Brown, 2010; Smith, 2000). Because overlay journals rely primarily on the IT infrastructure used to create a preprint server, their costs tend to be lower than the costs of a traditional journal. The costs to support these overlay journals should therefore be within reach of existing scientific societies. The existence of these journals should provide competitive alternatives to African authors wishing to publish their research.

A second pitfall relates to the existence of institutionalized practices that exploit African researchers, such as the misappropriation of research funds (Ojiji, 2015) or guest authorship by researchers in positions of power (Rohwer et al., 2017). These practices are certainly not restricted to Africa, but the political instability in the wake of de-colonization has entrenched such practices in some African countries (Kirya, 2019; Lawal, 2007). Such entrenched practices may require the establishment of institutional research integrity offices that are led by Africans but supported, morally and financially, by North American and European researchers. These African research integrity offices should be non-profit, independent, and internationally affiliated organizations with a mission to improve research credibility, and research fund management and performance.

A final pitfall is the risk of research colonization (Boshoff, 2009), in which African research partners are treated as "data collectors" for a foreign collaborator and are given insufficient credit and funds for their contributions. Part of what complicates this issue is that ethical intuitions may differ across countries. Moreover, due to the highly varying levels of development across countries, researchers may enter collaborations with wildly different expectations about what constitutes "sufficient" compensation. We believe the adoption of 
contributorship systems (Holcombe, 2019), in which authors explicitly document finegrained contributions to research papers in, for example, the article author notes, can at least make visible when credit is out of sync with contributions. As a side benefit, more robust systems of contributorship could also illuminate the problem of guest authorship by powerful researchers. Explicit collaboration agreements that lay out expected project contributions and systems of compensation ahead of time can also help align the expectations of all parties in a collaboration, thereby mitigating the risk that one party feels exploited (see Forscher, Wagenmakers, et al., 2020). Ultimately, to cope with the possibility of differing ethical intuitions across cultures, the Committee on Publication Ethics (https://publicationethics.org/about/governance) may need to co-design guidance about managing ethical concerns in international collaborations with the input of African scientists.

\section{Conclusion}

Psychology in North America, Europe, and Australia and science in Africa are both at pivotal moments where they have the potential to make lasting improvements. This potential exists because of the credibility revolution on the one hand and the push for human development on the other. We believe these two movements can benefit each other. The credibility revolution can benefit through engaging researchers of different perspectives to solve problems that concern a greater slice of humanity. African science can benefit from open science practices that use open infrastructure and enhance research credibility. We hope both these movements take advantage of this crossroads to change themselves for the better. 


\section{References}

Arnett, J. J. (2009). The neglected 95\%, a challenge to psychology's philosophy of science. American Psychologist, 64(6), 571-574. https://doi.org/10.1037/a0016723

Atickem, A., Stenseth, N. Chr., Fashing, P. J., Nguyen, N., Chapman, C. A., Bekele, A., Mekonnen, A., Omeja, P. A., \& Kalbitzer, U. (2019). Build science in Africa. Nature, 570(7761), 297-300. https://doi.org/10.1038/d41586-019-01885-1

Bem, D. J. (2011). Feeling the future: Experimental evidence for anomalous retroactive influences on cognition and affect. Journal of Personality and Social Psychology, 100(3), 407-425. https://doi.org/10.1037/a0021524

Bloom, D. E., Canning, D., Chan, K., \& Luca, D. L. (2014). Higher Education and Economic Growth in Africa. International Journal of African Higher Education, 1(1). https://doi.org/10.6017/ijahe.v1i1.5643

Boshoff, N. (2009). Neo-colonialism and research collaboration in Central Africa. Scientometrics, 81(2), 413-434. https://doi.org/10.1007/s11192-008-2211-8

Brown, J. (2010). An introduction to overlay journals. Repositories Support Project. https://discovery.ucl.ac.uk/id/eprint/19081

Byers-Heinlein, K., Bergmann, C., Davies, C., Frank, M. C., Hamlin, J. K., Kline, M., Kominsky, J. F., Kosie, J. E., Lew-Williams, C., Liu, L., Mastroberardino, M., Singh, L., Waddell, C. P. G., Zettersten, M., \& Soderstrom, M. (2020). Building a collaborative psychological science: Lessons learned from ManyBabies 1. Canadian Psychology/Psychologie Canadienne, 61(4), 349-363.

https://doi.org/10.1037/cap0000216

Draft text of the UNESCO Recommendation on Open Science (SC-PCB-SPP/2021/OSIGM/WD3). (2021). UNESCO. 
Ebersole, C. R., Axt, J. R., \& Nosek, B. A. (2016). Scientists’ Reputations Are Based on Getting It Right, Not Being Right. PLOS Biology, 14(5), e1002460. https://doi.org/10.1371/journal.pbio.1002460

Fearon, J. D. (2003). Ethnic and Cultural Diversity by Country. Journal of Economic Growth, $8,195-222$.

Fecher, B., \& Friesike, S. (2014). Open Science: One Term, Five Schools of Thought. In S. Bartling \& S. Friesike (Eds.), Opening Science (pp. 17-47). Springer International Publishing. https://doi.org/10.1007/978-3-319-00026-8_2

Forscher, P. S., Paris, B., Primbs, M., \& Coles, N. A. (2020). PSACR: The Psychological Science Accelerator's COVID-19 Rapid-Response Project [Preprint]. PsyArXiv. https://doi.org/10.31234/osf.io/x976j

Forscher, P. S., Wagenmakers, E.-J., Coles, N. A., Silan, M. A., Dutra, N. B., BasnightBrown, D., \& IJzerman, H. (2020). The Benefits, Barriers, and Risks of Big Team Science [Preprint]. PsyArXiv. https://doi.org/10.31234/osf.io/2mdxh

Francis, G. (2012). Too good to be true: Publication bias in two prominent studies from experimental psychology. Psychonomic Bulletin \& Review, 19(2), 151-156. https://doi.org/10.3758/s13423-012-0227-9

Gervais, W. M. (2020). Practical Methodological Reform Needs Good Theory [Preprint]. PsyArXiv. https://doi.org/10.31234/osf.io/jcs6e

Hansen, N., \& Heu, L. (2020). All Human, yet Different: An Emic-Etic Approach to CrossCultural Replication in Social Psychology. Social Psychology, 51(6), 361-369. https://doi.org/10.1027/1864-9335/a000436

Henrich, J., Heine, S. J., \& Norenzayan, A. (2010). The weirdest people in the world? Behavioral and Brain Sciences, 33(2-3), 61-83. https://doi.org/10.1017/S0140525X0999152X 
Holcombe, A. O. (2019). Contributorship, Not Authorship: Use CRediT to Indicate Who Did What. Publications, 7(3), 48. https://doi.org/10.3390/publications7030048

Hountondji, P. (1990). Scientific Dependence in Africa Today. Research in African Literatures, 21(3), 5-15.

Huang, C.-K. (Karl), Neylon, C., Hosking, R., Montgomery, L., Wilson, K. S., Ozaygen, A., \& Brookes-Kenworthy, C. (2020). Evaluating the impact of open access policies on research institutions. ELife, 9, e57067. https://doi.org/10.7554/eLife.57067

ICEF Monitor. (2015, March 16). African summit calls for major expansion of higher education. https://monitor.icef.com/2015/03/african-summit-calls-for-majorexpansion-of-higher-education/

Kaplan, R. M., \& Irvin, V. L. (2015). Likelihood of Null Effects of Large NHLBI Clinical Trials Has Increased over Time. PLOS ONE, 10(8), e0132382. https://doi.org/10.1371/journal.pone.0132382

Kirya, M. (2019). Corruption in universities: Paths to integrity in the higher education subsector (U4 Issue 2019:10). Anti-Corruption Resource Centre. https://data.opendevelopmentmekong.net/dataset/0d23d14c-5ec4-45ca-95b0d4997e7dd713/resource/d0daa8be-8cd3-44f4-9d47be2af130a324/download/u4_corruption-in-universities_paths-to-integrity-in-thehigher-education-subsector.pdf

Lakens, D. (2019). The Value of Preregistration for Psychological Science: A Conceptual Analysis [Preprint]. PsyArXiv. https://doi.org/10.31234/osf.io/jbh4w

Lawal, G. (2007). Corruption and Development in Africa: Challenges for Political and Economic Change. Humanity and Social Sciences Journal, 2, 1-7.

Michalopoulos, S., \& Papaioannou, E. (2020). Historical Legacies and African Development. Journal of Economic Literature, 58(1), 53-128. https://doi.org/10.1257/jel.20181447 
Moshontz, H., Binion, G. E., Walton, H., Brown, B. T., \& Syed, M. (2020). A Guide to Posting and Managing Preprints [Preprint]. PsyArXiv. https://doi.org/10.31234/osf.io/dp4x9

Mouton, J., \& Valentine, A. (2017). The extent of South African authored articles in predatory journals. South African Journal of Science, 113(7/8). https://doi.org/10.17159/sajs.2017/20170010

Mwangi, K., Mainye, B., Ouso, D., Kevin, E., Muraya, A., Kamonde, C., Naitore, C., Pauline, K., Gilbert, K., Musundi, S., Mutisya, J., mwangi, E., Mgawe, C., Miruka, S., \& Kibet, C. K. (2021). Open Science in Kenya: Where are we? [Preprint]. AfricArXiv. https://doi.org/10.31730/osf.io/mgkw3

Nabyonga-Orem, J., Asamani, J. A., Nyirenda, T., \& Abimbola, S. (2020). Article processing charges are stalling the progress of African researchers: A call for urgent reforms. BMJ Global Health, 5(9), e003650. https://doi.org/10.1136/bmjgh-2020-003650

Nordling, L. (2018). World Bank pours hundreds of millions into African science. Nature, 561(7721), 16-16. https://doi.org/10.1038/d41586-018-06094-w

Nosek, B. A., Hardwicke, T. E., Moshontz, H., Allard, A., Corker, K. S., Dreber, A., Fidler, F., Hilgard, J., Kline Struhl, M., Nuijten, M. B., Rohrer, J. M., Romero, F., Scheel, A. M., Scherer, L. D., Schönbrodt, F. D., \& Vazire, S. (2021). Replicability, Robustness, and Reproducibility in Psychological Science [Preprint]. PsyArXiv. https://doi.org/10.31234/osf.io/ksfvq

Nsamenang, A. B. (2007). Origins and development of scientific psychology in Afrique Noire. In Psychology: IUPsyS Global Resource (2007th ed.). Psychology Press. http://citeseerx.ist.psu.edu/viewdoc/download?doi=10.1.1.522.4330\&rep=rep1\&type= pdf 
Ojiji, O. O. (2015). Fifty Years of Psychology in Nigeria: Are We Still Teaching Science or Folktales? African Journal for the Psychological Studies of Social Issues, 18(2). http://www.ajpssi.org/index.php/ajpssi/article/view/129

Onie, S. (2020). Redesign open science for Asia, Africa and Latin America. Nature, 587(7832), 35-37. https://doi.org/10.1038/d41586-020-03052-3

Paris, B., IJzerman, H., \& Forscher, P. S. (2020). PSA 2020-2021 Study Capacity Report [Preprint]. PsyArXiv. https://doi.org/10.31234/osf.io/v9zma

Premachandra, B., \& Lewis, N. A. (2020). v[Preprint]. PsyArXiv. https://doi.org/10.31234/osf.io/nr8kh

Rohwer, A., Young, T., Wager, E., \& Garner, P. (2017). Authorship, plagiarism and conflict of interest: Views and practices from low/middle-income country health researchers. BMJ Open, 7(11), e018467. https://doi.org/10.1136/bmjopen-2017-018467

Roser, M. (2013). Economic Growth. Our World In Data. https://ourworldindata.org/economic-growth

Roser, M., Ritchie, H., \& Ortiz-Ospina, E. (2013). World Population Growth. Our World In Data. https://ourworldindata.org/world-population-growth

Saab, R., Ayanian, A. H., \& Hawi, D. R. (2020). The Status of Arabic Social Psychology: A Review of 21st-Century Research Articles. Social Psychological and Personality Science, 11(7), 917-927. https://doi.org/10.1177/1948550620925224

Scheel, A. M., Schijen, M., \& Lakens, D. (2020). An excess of positive results: Comparing the standard Psychology literature with Registered Reports [Preprint]. PsyArXiv. https://doi.org/10.31234/osf.io/p6e9c

Schimmack, U. (2012). The ironic effect of significant results on the credibility of multiplestudy articles. Psychological Methods, 17(4), 551-566. https://doi.org/10.1037/a0029487 
Shrout, P. E., \& Rodgers, J. L. (2018). Psychology, Science, and Knowledge Construction: Broadening Perspectives from the Replication Crisis. Annual Review of Psychology, 69(1), 487-510. https://doi.org/10.1146/annurev-psych-122216-011845

Smith, A. P. (2000). The journal as an overlay on preprint databases. Learned Publishing, 13(1), 43-48. https://doi.org/10.1087/09531510050145542

Spellman, B. A. (2015). A Short (Personal) Future History of Revolution 2.0. Perspectives on Psychological Science, 10(6), 886-899. https://doi.org/10.1177/1745691615609918

The World Bank Group \& Elsevier. (2014). A Decade of Development in Sub-Saharan African Science, Technology, Engineering \& Mathematics Research (No. 91016). worldbank.org/africa/stemresearchreport

Tiokhin, L., Hackman, J., Munira, S., Jesmin, K., \& Hruschka, D. (2019). Generalizability is not optional: Insights from a cross-cultural study of social discounting. Royal Society Open Science, 6(2), 181386. https://doi.org/10.1098/rsos.181386

Vazire, S. (2017). Quality Uncertainty Erodes Trust in Science. Collabra: Psychology, 3(1), 1. https://doi.org/10.1525/collabra.74

Vazire, S. (2018). Implications of the Credibility Revolution for Productivity, Creativity, and Progress. Perspectives on Psychological Science, 13(4), 411-417. https://doi.org/10.1177/1745691617751884

Wagge, J. R., Baciu, C., Banas, K., Nadler, J. T., Schwarz, S., Weisberg, Y., IJzerman, H., Legate, N., \& Grahe, J. (2019). A Demonstration of the Collaborative Replication and Education Project: Replication Attempts of the Red-Romance Effect. Collabra: Psychology, 5(1), 5. https://doi.org/10.1525/collabra.177

Wagge, J. R., Brandt, M. J., Lazarevic, L. B., Legate, N., Christopherson, C., Wiggins, B., \& Grahe, J. E. (2019). Publishing Research With Undergraduate Students via 
Replication Work: The Collaborative Replications and Education Project. Frontiers in Psychology, 10, 247. https://doi.org/10.3389/fpsyg.2019.00247

Xia, J., Harmon, J. L., Connolly, K. G., Donnelly, R. M., Anderson, M. R., \& Howard, H. A. (2015). Who publishes in "predatory" journals? Journal of the Association for Information Science and Technology, 66(7), 1406-1417.

https://doi.org/10.1002/asi.23265

Young, C. (2012). The postcolonial state in Africa: Fifty years of independence, 1960-2010. The University of Wisconsin Press. 